\title{
Imagens da escravidão na Antiguidade como meios de auto-representação*
}

\section{Slave images in Antiquity as self-representation $^{\star *}$}

\author{
ANDREA BINSFELD \\ Forschungen zur antiken Sklaverei \\ Akademie der Wissenschaften und der Literatur, Mainz \\ Arbeitsstelle Trier \\ Universität Trier \\ $D-54286$ Trier \\ binsfeld@uni-trier.de
}

RESUMO O artigo mostra, mediante exemplos iconográficos, as dificuldades metodológicas de identificação de escravos em obras de arte antigas, mas, também, as possibilidades de se obter informações adicionais às fontes literárias. Ainda que, muitas vezes, sejam necessárias inscrições ou fontes escritas adicionais para se definir com exatidão o estatuto jurídico das pessoas representadas, os monumentos transportam, de maneira sutil, informação de outra qualidade sobre a relação senhor-escravo e sobre a auto-compreensão de senhores e de escravos. Algumas das obras até nos oferecem perspectivas dos próprios escravos, que nas fontes escritas são muito raras.

* Artigo recebido em: 30/01/2009. Autor convidado.

** Sven Korzilius, Universität Trier. Revisão Técnica: Eduardo França Paiva, UFMG. 
Palavras-chave iconografia, tráfico de escravos, cativeiro, auto-representação, escravidão antiga

ABSTRACT The article shows, using iconographic examples, the methodological difficulties of identifying slaves in ancient works of Art, but also the possibilities for additional information on literary sources. Often are necessary additional inscriptions or written sources to define accurately the legal status of the persons represented. But the monuments offer, so subtle, other kind of information on the master-slave relationship and on the self-understanding of masters and slaves. Some of the works of Art offer the perspectives of slaves, that in the written sources are very rare.

Keywords iconography, slave trade, captivity, self-representation, Ancient slavery

Hoje em dia, o filme é um meio importante para a difusão de imagens sobre a escravidão antiga. Assim, um dos escravos mais conhecidos da Antiguidade, Espártaco, a cabeça da insurreição de escravos entre 73 e 71 a.C., atualmente, para muitos, é ligado ao rosto de Kirk Douglas, por causa do filme Spartacus, de Stanley Kubrick. Filmes sobre a Antiguidade, como Gladiador, de Ridley Scott, são muitas vezes inspirados pela pintura de gênero do século XIX. Por exemplo, os quadros de Jean-Léon Gérôme mostram o gosto de seus contemporâneos por temáticas antigas ou exoticas, como lutas de gladiadores ou vendas de escravas (Figura 1). ${ }^{1}$ Gérôme emprega em suas pinturas estereótipos de todos os tempos e impressões que adquiriu em suas viagens ao Egito. Por exemplo, ele colocava uma cena específica de uma venda em um quadro "oriental" e em outra ocasião colocava a mesma cena em um ambiente da "Antiguidade". É verdade que o pintor tentou obter precisão histórica e de expert da Antiguidade, mas resta saber até que ponto ele acertou a realidade antiga. ${ }^{2}$ Uma vantagem na análise de suas obras é, sem dúvida, que nós conhecemos sempre os títulos, de maneira que não surgem dúvidas sobre a condição de cativo das pessoas representadas. Em comparação a isso, a interpretação de obras gráficas ou plásticas da própria Antiguidade é muito mais difícil, como, por exemplo, obras que muitos pesquisadores interpretam como representações de vendas de escravos ou escravas. Vejamos alguns casos.

1 DEISSLER, Johannes. Realitätsgetreues Abbild oder künstlerische Interpretation eines römischen Sklavenverkaufs? Zu Jean-Léon Gérômes Vente d'esclaves à Rome. In: Menschenraub, Menschenhandel und Sklaverei in antiker und moderner Perspektive. Stuttgart: H. Heinen, 2008, p.183-194.

2 Vgl. dazu JUNKELMANN, Marcus. Hollywoods Traum von Rom. Mainz, 2004, p.61-69. 


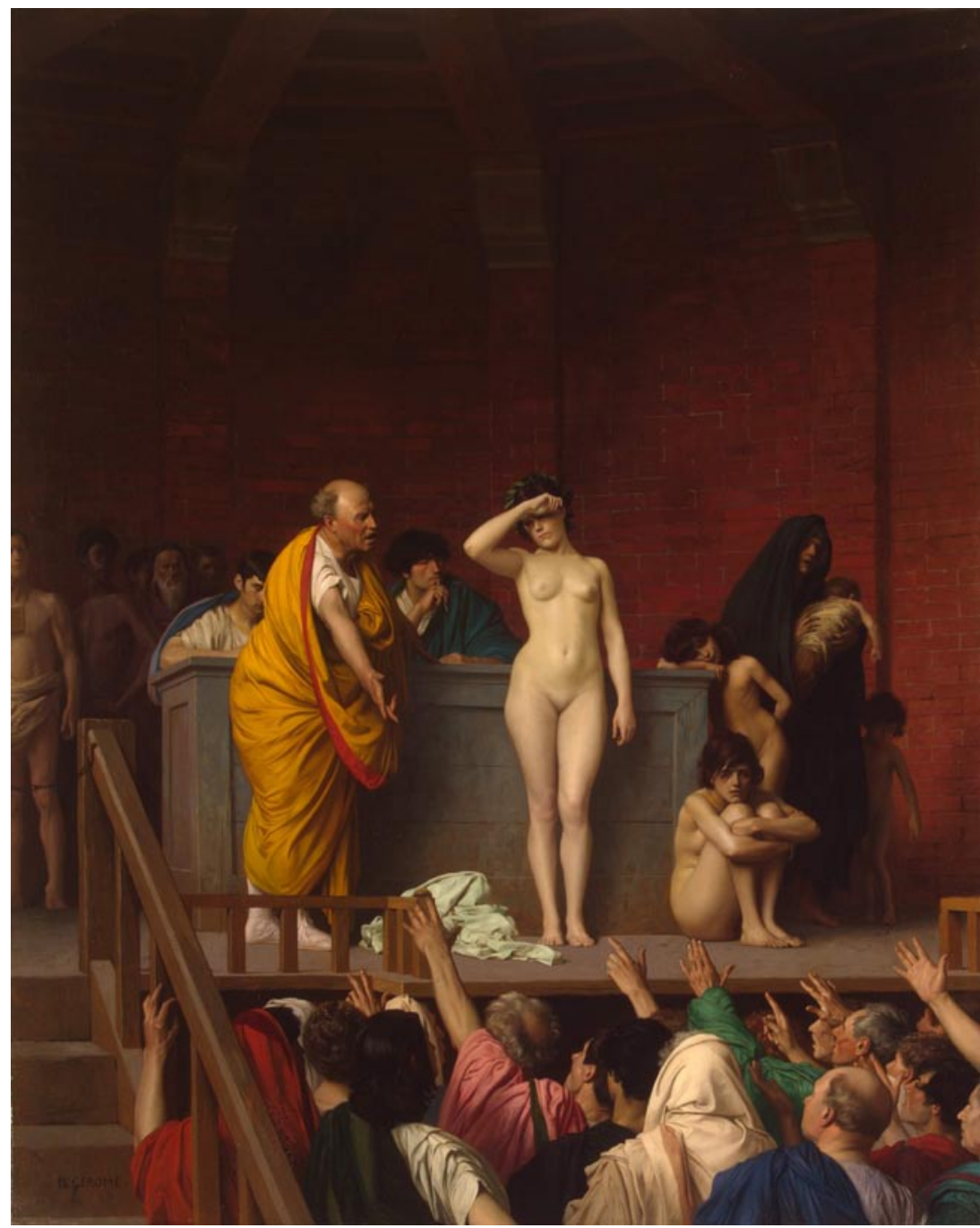

Figura 1: Jean Léon Gèrôme: Vente d'esclaves à Rome, 1884. St. Petersburg, Ermitage. (CThe State Hermitage Museum, GE-6294).

\section{A representação da "mercardoria humana" em monumentos sepulcrais antigos}

Em uma coluna sepulcral da tardia república romana de São Angelo in Formis, perto de Capua, ${ }^{3}$ vemos na imagem principal duas pessoas iden-

3 Capua, Museo Provinciale Campano, inv.70; GUMMERUS, Herman. Darstellung eines Sklavenverkaufs auf einem Grabstein in Capua. Klio, v.12, p.500-503, 1912; DONDERER, Michael; SPILIOPOULOU-DONDERER, Ioanna. Spätrepublikanische und kaiserzeitliche Grabmonumente von Sklavenhändlern. Gymnasium, v.100, p.254-266, v.a. p.254-256, v.a., p. 255, 1993. 
tificadas na inscrição como M(arcus) Publius Satur, liberto de Marcus, e o liberto Marcus Publilius Stephanus. Os dois então são ex-escravos, mas, no monumento sepulcral, se deixam representar vestidos de toga, o vestido então reservado aos cidadãos. Uma outra inscrição informa que Marcus Publilius Cadia, praeco (pregoeiro), e Marcus Publilius Timotes, ambos libertos de Marcus, mandaram erguer a pedra sepulcral. ${ }^{4}$

Para o tema da venda de escravos interessa o relevo debaixo desta imagem principal (Figura 2): no centro vemos, em um estrado, uma figura masculina nua, à direita, um homem vestido de toga, à esquerda, um homem vestido de túnica. Ambos fazem gestos em direção à pessoa nua no estrado. O violento gesto do homem do lado esquerdo é acentuado pelo seu manto abalofado. Hermann Gummerus foi o primeiro a interpretar esta cena como venda de um escravo. Segundo sua opinião, o homem à esquerda é o pregoeiro Publilius Cadia mencionado pela inscrição, aqui mostrado na sua profissão, apregoando durante uma arrematação de escravos. Gummerus identificou o homem à direita como Marcus Publilius Satur, quem, segundo a interpretação dele, foi um vendedor de escravos, representado no relevo como tal. Leonhard Schumacher não duvida da interpretação do relevo como venda de um escravo, ${ }^{5}$ mas ele relaciona a cena com o sepulto Saturus e o seo liberto Stephanus. Segundo Schumacher, a cena mostra a compra de Stephanus (no centro) por Saturus (à direita). A pessoa à esquerda então podia ser Cadia, como leiloeiro. Já Donderer, contrário à essa leitura, acha inverossímil um ex-escravo mandar mostrar no seu túmulo justamente o ato de sua compra. ${ }^{6}$

Comparando a composição do relevo sepulcral antigo e da Vente d'esclaves à Rome de Jean-Léon Gérôme, aparecem alguns paralelos. A linguagem corporal do leiloeiro no quadro do século XIX, que apregoa a sua "mercardoria" diante de eventuais compradores, é parecida com os gestos do homem à esquerda no relevo antigo; o homem vestido de toga podia representar um dos potenciais compradores. Muitos detalhes indicam então que o relevo pode ser interpretado como a venda de um escravo; se bem que as pessoas da cena não podem ser relacionadas indubitávelmente às pessoas mencionadas pela inscrição.

O paralelo da composição do relevo com a do quadro de Gérôme podia sustentar a interpretação de ser uma venda de escravo no caso do primeiro, mas considerando que entre as duas obras passaram-se quase dois mil anos, temos que nos perguntar se esses paralelos são um mero acaso ou se resultam do fato de ambas as obras empregarem motivos semelhantes, existentes nas realidades retratadas, e atemporais. A interpretação do

SCHUMACHER, Leonhard. Sklaverei in der Antike. Altag und Schicksal der Unfreien. München, 2001, p.55f.

DONDERER, Michael. Spätrepublikanische und kaiserzeitliche Grabmonumente von Sklavenhändlern, p.256f. 
relevo como venda de um escravo foi posta em dúvida. Uma interpretação alternativa quer definir a figura central não como escravo, mas como estátua numa base, significando uma praça pública. ${ }^{7}$

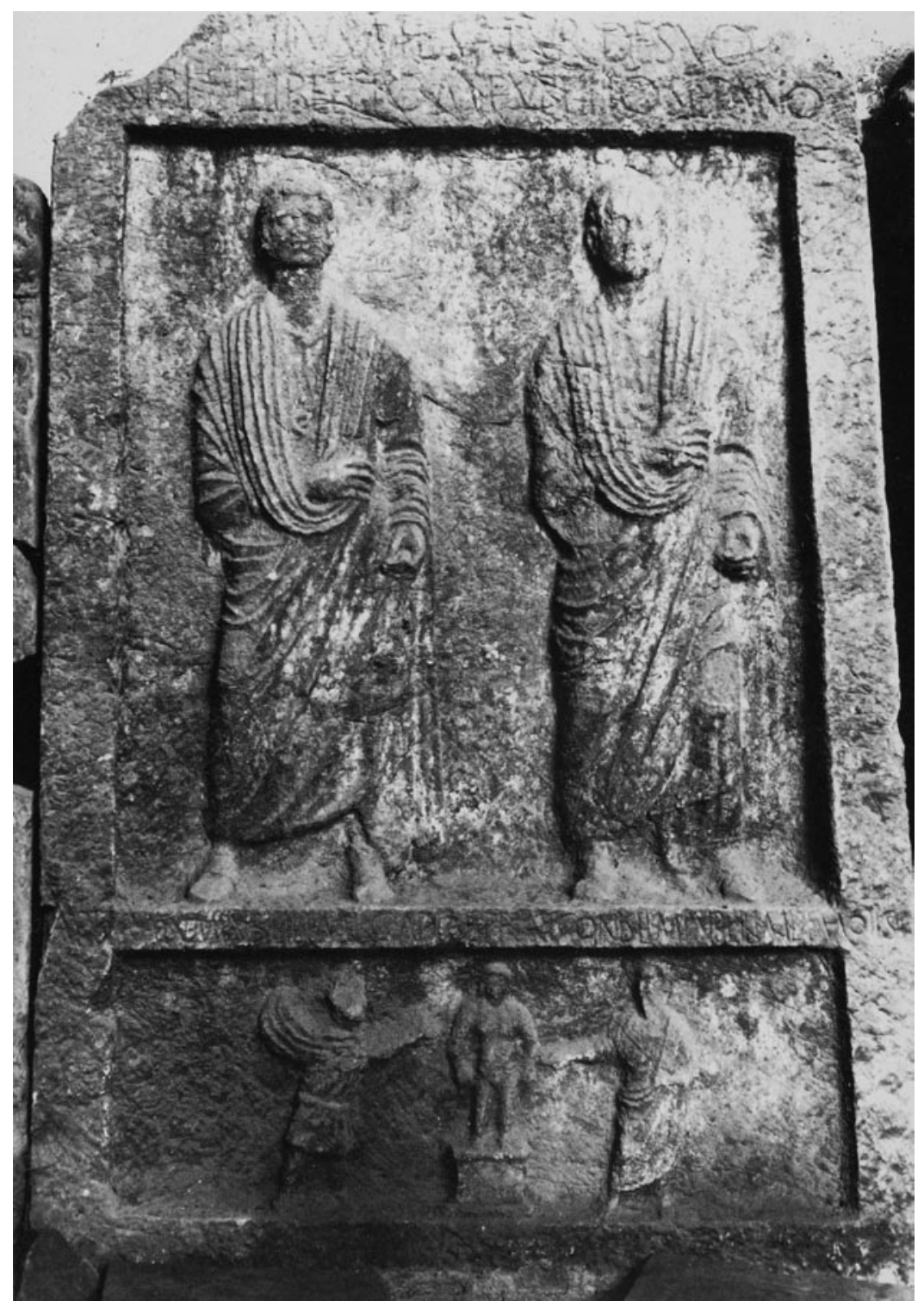

Figura 2: Coluna sepulcral de S. Angelo in Formis perto de Capua, Capua, Museo Provinciale Campano, inv.70. (Ilustração em: DONDERER, Michael. Spätrepublikanische und kaiserzeitliche Grabmonumente von Sklavenhändlern, II.3).

7 GUMMERUS, Herman. Darstellung eines Sklavenverkaufs auf einem Grabstein in Capua, p.502. 
Para ter mais segurança, comparamos, então, o relevo de Capua com outras obras da Antiguidade. Um relevo sepulcral de Arlon (Figura 3), da época imperial romana, do qual hoje em dia só existe um desenho, também é interpretado como uma venda de escravo. ${ }^{8}$ Como no relevo de Capua, a cena é composta de três personagens: no centro, uma pessoa quase nua, à direita um homem vestido de toga, com uma mão elevada, e à esquerda um homem vestido de uma capa de capucha gaulesa. A figura quase nua é interpretada como sendo um escravo examinado pelo comprador, o homem de toga à direita como pregoeiro, apresentando o escravo ao modo de seu correspondente no relevo de Capua, e o homem de capa, como comprador, examinando o escravo profundamente e dando sinais ao pregoeiro com sua mão direita. Segundo a inscrição, a pedra sepulcral foi erecta pelo patronus Attilius Regulus como herdeiro de seu liberto. ${ }^{9}$ Mas qual é a relação entre a cena no relevo e a inscrição? O patrão queria - como Schumacher sugere - fazer lembrar a compra de seu ex-escravo, para quem mandou erguer a pedra sepulcral? ${ }^{10}$

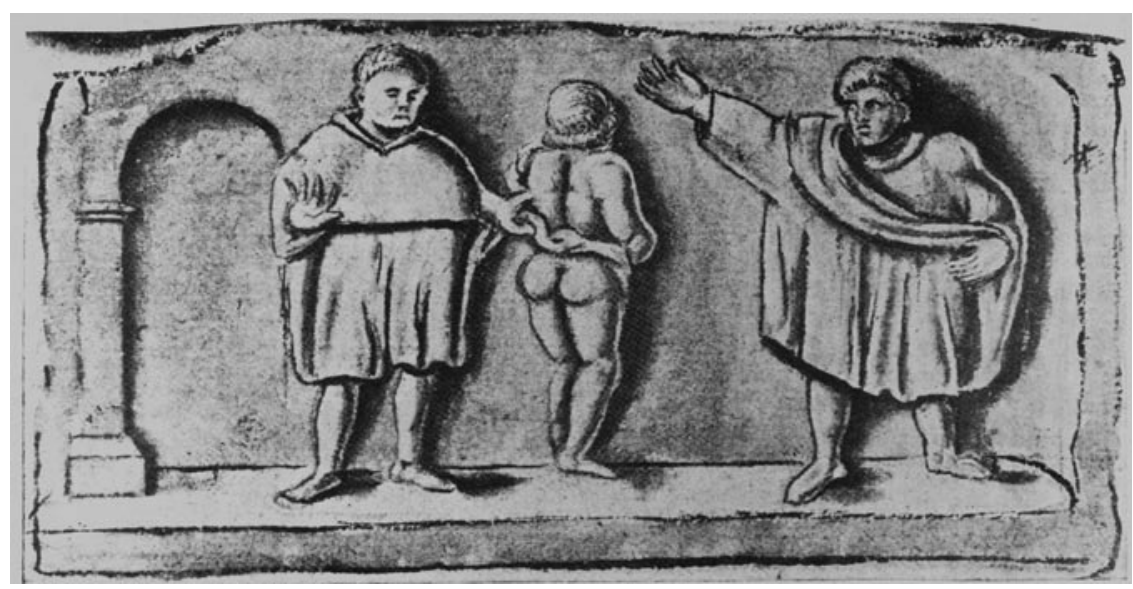

Figura 3: Relevo sepulcral de Arlon, desenho segundo Alexander Wiltheim. (llustração em: DONDERER, Michael. Spätrepublikanische und kaiserzeitliche Grabmonumente von Sklavenhändlern, II.2).

$\mathrm{Na}$ interpretação de tais relevos temos de ter em conta, sobretudo, a intenção do fundador. O seu âmbito prinicpal na plasmação de um monumento sepulcral é a representação. Os monumentos sepulcrais refletem as experiências sociais do fundador e/ou do sepultado, quem, consciente

8 SCHUMACHER, Leonhard. Sklaverei in der Antike. Alltag und Schicksal der Unfreien, p.57f.; LAUM, Bernhard. Sklavenversteigerung auf einem römischen Relief von Arlon. Germania, v.2, p.108-112, 1918.

9 CIL XIII 3986: /Attilius Regulus /patronus idemque heres//D(is) M(anibus) /pat(roni) /s(ui) f(aciendum) c(uravit). Schumacher, Leonhard. Sklaverei in der Antike. Alltag und Schicksal der Unfreien, p.58 löst dagegen auf: P(ubli) Attitil $P($ ubli) I(iberti)] Sec[uri] (?) f(aciendum) c(uravit), was den Sinn der Inschrift wohl eher trifft. Da der Stein verschollen ist, ist eine Überprüfung der Lesung am Stein jedoch nicht mehr möglich.

10 SCHUMACHER, Leonhard. Sklaverei in der Antike. Alltag und Schicksal der Unfreien, p.55s. 
de si, ostenta o seu estado sócio-econômico, ${ }^{11}$ manifesto na posse, no número e na qualificação de escravos e criados. As pedras sepulcrais, na maioria dos casos, não servem para representar os escravos e libertos, mas servem para a auto-representação do senhor. Resta, a respeito de muitos monumentos, perguntar se o fundador queria mostrar que ele ganhara o seu elevado estado socio-económico por tráfico de escravos ou se ele era um senhor e que queria simbolizar sua riqueza pela capacidade de comprar escravos. As duas possibilidades podem corresponder à intenção dos monumentos sepulcrais, pois uma afirmação exata é quase impossível se não houver uma inscrição inequívoca.

No relevo de um vendedor de escravos de Anfípolis (Macedônia) existe uma inscrição inequívoca. Nela, o sepultado Aulos Kapreilios Timotheos, liberto de Aulos, é identificado pela insrição como somatemporos - traficante de escravos (Figura 4).12 Por causa desta inscrição podemos interpretar grande parte do relevo sem problemas. No registo baixo vemos uma fila de oito homens, todos ligados por uma corrente no pescoço, dirigidos por um homem de capa de capucha. Seguem-se duas mulheres, cada uma com uma criança. Sem duvida se trata dum transporte de cativos para serem vendidos como escravos. A inscrição comunica que Kapreilios Timotheos aqui fez mostrar cenas de sua vida profissional.

\section{Arqueologia e escravidão - uma combinação problemática?}

Este relance sobre vendas de escravos na arte plástica mostra de maneira exemplar as dificuldades da interpretação de representações de escravos em obras da Antiguidade. Sem tradição escrita (no caso ideal, uma inscrição) a identificação de figuras como escravos ou escravas é extremamente difícil. Por isso, até agora há poucas pesquisas sobre a representação de escravos na arte antiga. Durante décadas, a investigação baseava-se em inscrições, papiros, fontes literárias e jurídicas. A Arqueologia clássica, em contrapartida, estava mais interessada em perguntas da História de Arte e negligenciava as questões da História Social, de maneira que as representações de escravos e libertos não tinham grande importância. Isto refletia a Bibliographie zur antiken Sklaverei (bibliografia da escravidão antiga): ${ }^{13}$ de mais de dez mil registos só 125 dizem respeito a pesquisas arqueologicas. Até os anos 60

11 FREIGANG, Yasmine. Die Grabdenkmäler der gallo-römischen Kultur im Moselland. Studien zur Selbstdarstellung einer Gesellschaft. Jahrbuch des Römisch-Germanischen Zentralmuseums, Mainz, v.44, p.277-440, 1997; LANGNER, Martin. Szenen aus Handwerk und Handel auf gallo-römischen Grabmälern. Jahrbuch des Deutschen Archäologischen Instituts, v.116, p.299-356, 2001; BINSFELD, Andrea. Arbeit - Status - Repräsentation. Sklaven und Freigelassene in Inschriften und Grabdenkmälern des Treverergebietes. Trierer Zeitschrift, v.69/70, p.167-176, 2006/7.

12 DUCHENE, Hervé. Sur la stèle d'Aulus Caprilius Timotheos, sômatemporos. Bulletin de Correspondance Hellénique, v.110, p.513-530, 1986.

13 BELLEN, Heinz e HEINEN, Heinz. (eds.) Bibliographie zur antiken Sklaverei. Neu bearbeitet von Dorothea Schäfer und Johannes Deißler auf Grundlage der von Elisabeth Herrmann in Verbindung mit Norbert Brockmeyer erstellten Ausgabe, 2. Bde. Stuttgart 2003. 
do século XX, a Arqueologia teve um papel menor na investigação da escravidão antiga. Só a partir de então, imagens de escravos e libertos começam a ser usadas como fontes para uma História Social. ${ }^{14}$ Assim, a investigação arqueológica começou a tentar deduzir a posição social dos sepultados e a organização da sociedade da decoração e organização espacial de campos sepulcrais. ${ }^{15}$ Debaixo dessas premissas, a Arqueologia fez e está fazendo importantes contribuições à investigação da escravidão. O enterro de escravos e libertos foi pesquisado visando questões sobre o estado das pessoas, sobre as estruturas sociais e de mobilidade social na sociedade grego-romana e, também, como representação dessa sociedade.

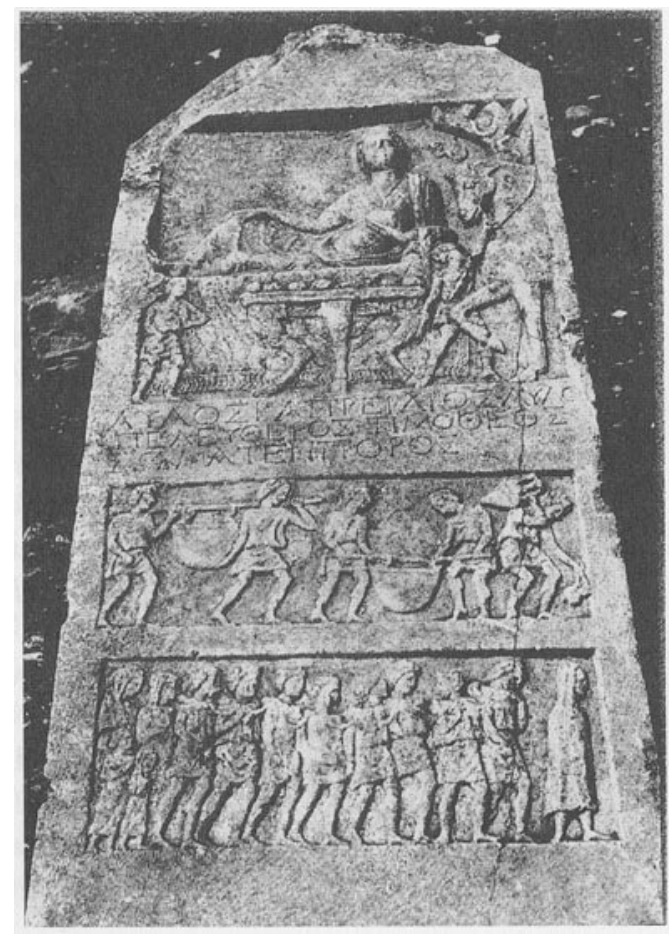

Figura 4: Anfípolis, Coluna sepulcral do traficante de escravos Aulus Cprilius Timotheos (llustração em: DUCHÊNE, Hervé. Sur la stèle d'Aulus Caprilius Timotheos, sômatemporos, Il.1).

14 SCHUMACHER, Leonhard. Sklaverei in der Antike. Alltag und Schicksal der Unfreien. Uma vista geral sobre a investigação arqueológica da escravidão oferece: MEYER, Elizabeth A. (ed.) Macmillan Encyclopedia of World Slavery. vol.I, 1998, p.82 (Archaeology of Slavery, Ancient World); HAUSER, Stefan. Quellen-Material. Historiker, Archäologen und das Schweigen der Steine. In: Methodische Perspektiven in der Klassischen Archäologie. Schriften des Deutschen Archäologen-Verbandes XVI. Tübingen, 2005, p.69-107; BINSFELD, Andrea. Handwörterbuch der antiken Sklaverei, v.I-II, 2008, v. sobretudo Archäologie.

15 VON HESBERG, Henner e ZANKER, Paul. (eds.) Römische Gräberstraßen. Selbstdarstellung - Status - Standard. München, 1987; KOCKEL, Valentin. Porträtreliefs stadtrömischer Grabbauten. Ein Beitrag zur Geschichte und zum Verständnis des spätrepublikanisch-frühkaiserzeitlichen Privatporträts. Mainz, 1993; ZANKER, Paul. Grabreliefs römischer Freigelassener. Jahrbuch des Deutschen Archäologischen Instituts, v.90, p.267-315, 1975; BERGEMANN, Johannes. Demos und Thanatos. Untersuchungen zum Wertsystem der Polis im Spiegel der attischen Grabreliefs des 4. Jahrhunderts v. Chr. und zur Funktion der gleichzeitigen Grabbauten. München, 1997. 
As situações habitacionais e de trabalho de escravos também foram focadas pela investigação. Frederick Thompson pesquisou traços de escravos na agricultura grega e romana, em pedreiras, minas e moinhos. Thompson descreve as tentativas de escavadores de definirem certas partes de villae rusticae como "senzalas" ou "quartéis de escravos" ou de localizar a presença de escravos por meio de peças de corrente ou ferros que pudessem ter sido utilisados para encadear escravos. Segundo Thompson, a interpretação deste material arqueologocio é impossível sem consideração das fontes escritas. ${ }^{16}$ Por isso, até hoje, poucas pesquisas tratam da iconografia da escravidão: o arqueólogo polaco Jerzy Wielowiejski, já em 1956, criticava publicações sobre a escravidão, afirmando que quase ignoravam o material arqueológico. ${ }^{17}$ Baseado em fontes literárias, Wielowiejski desenvolveu critérios para a identificação de escravos na arte da Grécia antiga, por exemplo, detalhes como o corte de cabelo, o vestuário, ${ }^{18}$ a fisionomia, o ofício ou um tamanho extremamente reduzido no baixo relevo, representado o estatuto social baixo. Em 1971, Nikolaus Himmelmann voltou ao problema da identificação de escravos na arte grega. ${ }^{19}$ Himmelmann nota uma grande dificuldade no fato dos escravos poderem ser representados no mesmo contexto, algumas vezes como estrangeiros, até feios e desfigurados, e outras vezes assimilados aos seus senhores. Segundo Himmelmann, as representações de escravos na arte clássica grega têm uma função programática e não devem ser interpretadas como retratos realistas, sobretudo, levando-se em consideração que os comitentes, na maioria dos casos, eram senhores, não escravos. Jerzy Kolendo, investigando imagens da escravidão na arte grega e romana, ${ }^{20}$ tenta identificar o estatuto das personagens através os seus trabalhos. Mas, principalmente em cenas que mostram artífices ou oficiais no trabalho, é muito dificil distinguir se são livres, libertos ou escravos. No caso de uma taça procedente de Vulci (hoje nos Museus Estaduais de Berlim), datada entre 490 e 480 a.C., que mostra o trabalho em uma fundição de minério (Figura 5), os investigadores costumam interpretar o operário sentado no chão, de pernas escarranchadas, como escravo, por causa de sua postura, que consideram indigna de um homem livre. Mais

16 THOMPSON, Frederick H. The Archaeology of Greek and Roman slavery. London, 2003. Uma crítica das tentativas de localizar quarteis de escravos com meios arqueologicos oferece: GEORGE, Michele. Servus and Domus: the slave in the Roman house. In: A. Wallace-Hadrill, domestic space in the Roman World. Pompeii and beyond. Portsmouth, 1997, p.15-24.

17 WIELOWIEJSKI, Jerzy. Zur Identifizierung der sklaven in der griechischen Kunst (poln.). Archeologia, Rocznik Instytutu Archeologii i Etnologii, Polskiej Akademii Nauk, v.8, p.266-272, 1956.

18 Para o problema do vestuario de escravos GEORGE, Michele. Slave disguise in Ancient Rome. Slavery and Abolition, v.23, p.41-54, 2002.

19 HIMMELMANN, Nikolaus. Archäologisches zum Problem der griechischen Sklaverei. Wiesbaden, 1971 (Abhandlungen der geistes- und sozialwissenschaftlichen Klasse 13). WEILER, Ingomar. Inverted Kalokagathia. In: WIEDEMANN, Th. e GARDNER, J. (eds.) Representing the Body of the Slave. Slavery and Abolition, v.23, n.2, p.11-28, 2002; WEILER, Ingomar. Überlegungen zur Physiognomie und Ikonographie in der antiken Sklaverei. In: POTNIA QHRWN. Festschrift für Gerda Schwarz zum 65. Geburtstag. Wien 2007, p.469-479.

20 KOLENDO, Jerzy. Éléments pour une enquête sur l'iconographie des esclaves dans l'art hellénistique et romain. In: SCHIAVITU. Manomissione e classi dipendenti nel mondo antico. Roma, 1979, p.161-174. 
dois operários ocupam-se de polir uma estátua. Um deles está vestido com um manto enrolado nas ancas e o outro está nu. O de manto é interpretado como livre, o despido (que tem um rosto feio), como escravo. ${ }^{21}$ Recentemente Leonhard Schumacher especificou cinco critérios para a identificação de escravos: a estatura; a posição isolada numa cena de grupo; trabalhos típicos de escravos; a fisionomia e, se houver inscrição, os nomes podem ser indícios para a falta de liberdade..$^{22}$

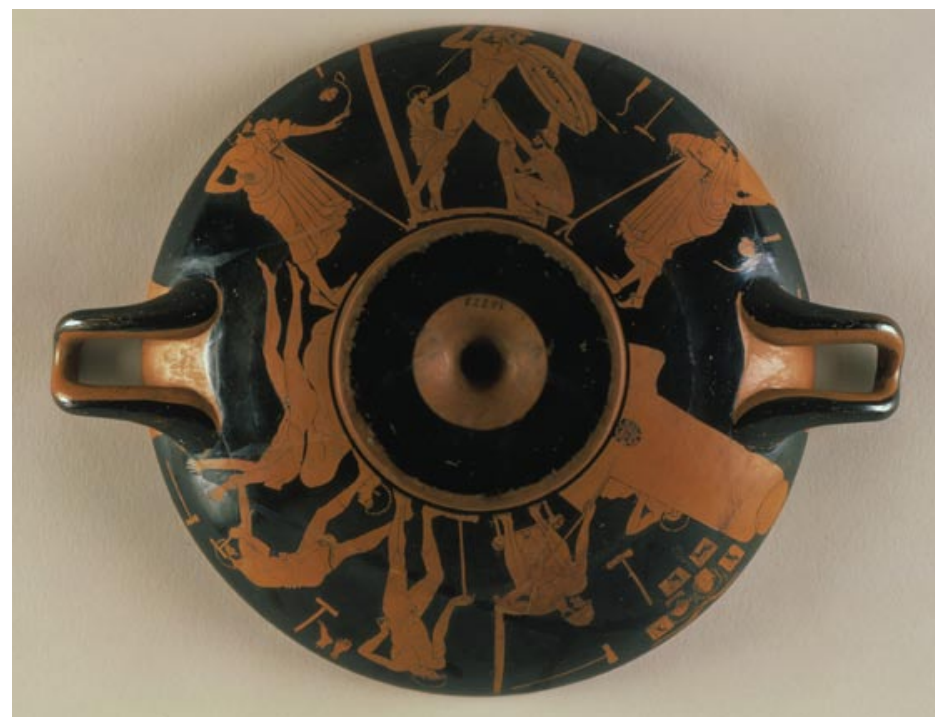

Figura 5: Taça grega de pintura vermelha do pintor da fundição de minério, Staatliche Museen zu Berlin, inv.F 2294. (@Bildarchiv Preussischer Kulturbesitz, Foto: Ingrid Geske).

\section{Senhores e escravos - uma pergunta de perspectiva}

Tentando sistematizar as imagens de escravos, podemos distinguir duas perspectivas. Em alguns (raros) casos, podemos perceber a perspectiva dos próprios escravos. Isso é o caso, por exemplo, quando escravos mandam erguer pedras sepulcrais para as suas crianças falecidas. É bem verdade que não sabemos, exatamente, até que ponto os escravos podiam financiar tais monumentos com seus pecúlios e em que medida os senhores podiam ter influência na realização dos monumentos sepulcrais. Mas, pelo menos em alguns casos, o auto-entendimento dos escravos se torna perceptível. Nas novas gerações eram depositadas todas as esperanças dos pais. Estas esperanças, ainda que frustradas, se achavam expressas nos monumentos

21 Staatliche Museen zu Berlin, inv. F 2294; HIMMELMANN, Nikolaus. Archäologisches zum Problem der Sklaverei, p.37f. Vgl. dazu auch ZANKER, Paul. Die Trunkene Alte. Frankfurt a.M. 1989, p.64-69.

22 SCHUMACHER, Leonhard. Sklaverei in der Antike. Alltag und Schicksal der Unfreien, p.65-90. 
sepulcrais, que, às vezes, eram plasmados luxuriosamente e mostravam as crianças escravas falecidas até em posturas e com atributos de deuses.

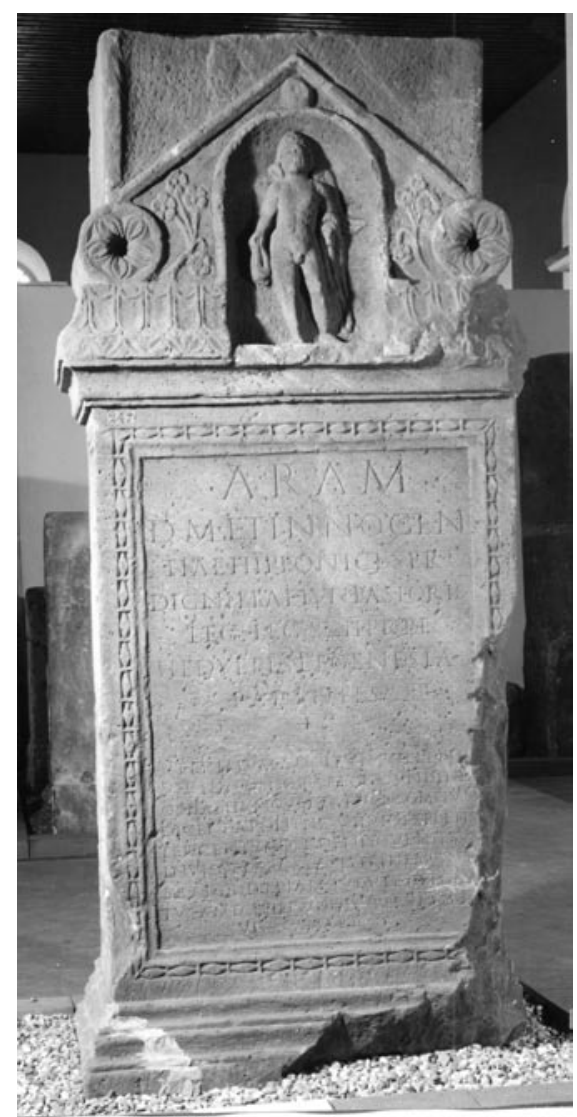

Figura 6: Representação de Hipponicus como Cupido numa pedra sepulcral de Mainz (llustração em: SELZER, Wolfgang. Römische Steindenkmäler. Mainz in römischer Zeit, II.30).

O altar sepulcral de Moguntiacum (Mogúncia ou Mainz, Alemanha), do $2^{\circ}$ século d.C., por exemplo, mostra um menino nu, com asas, com um manto enrolado no braço, empunhando um cajado (Figura 6). A inscrição informa que se trata do túmulo do escravo Hipponicus, mandado fazer por seus pais, Hedyepes e Genesia. No poema sepulcral, os pais lamentam a morte prematura do filho, que morreu com menos de um ano de idade. Eles comparam a sua graça com a de Cupido e de Apolo. ${ }^{23}$ Também neste

23 Rheinisches Landesmuseum Mainz, inv. S 612; SELZER, Wolfgang. Römische Steindenkmäler. Mainz in römischer Zeit. Mainz, 1988, Nr. 133; CIL XIII 6808 = CLE 1590: Aram d(is) M(anibus) et innocentiae Hipponici ser(vi) Dignillae lun(ii) Pastoris |Leg(ati) leg(ionis) XXII Pr(imigeniae) P(iae) F(idelis|Hedyepes et Genesia|parentes |ut primum adolevit pollens viribus decora facie |cupidinis os habitumque gerens |nec metuam dicere apollineus | huic expletis 
caso a inscrição facilita a interpretação do relevo. Obviamente, a criança morta, Hipponicus, é representada como Cupido. Trata-se de uma forma de deificação sepulcral, uma consecratio in formam deorum. ${ }^{24}$ Representantes de uma tal "deificação privada" pertenciam, muitas vezes, a esferas sociais com fortes chances de ascensão social: principalmente os libertos, mas, também, os escravos desejosos da manumissão, especialmente os muito próximos dos senhores. O monumento sepulcral oferece a esses escravos a possibilidade de exprimirem sua posição elevada e de se distinguirem dos demais. O luto dos pais, nesses casos, era misturado com a forte vontade de auto-representação, em combinação com a esperança frustrada da criança ter podido viver em liberdade. A intensidade dessa esperança para uma vida melhor das crianças (e da respectiva frustração por causa da morte) se mostra muito bem em monumentos sepulcrais de libertos, como, por exemplo, o dos Servilii (Figura 7), ${ }^{25}$ uma representação de um casal com o filho. O filho é decorado com os atributos de livre, uma bulla (um tipo de amuleto) e uma toga praetexta. A inscrição acentua esse estado de livre. Aí se mostrava o orgulho específico dos libertos, de seus filhos e da superação do estado servil.

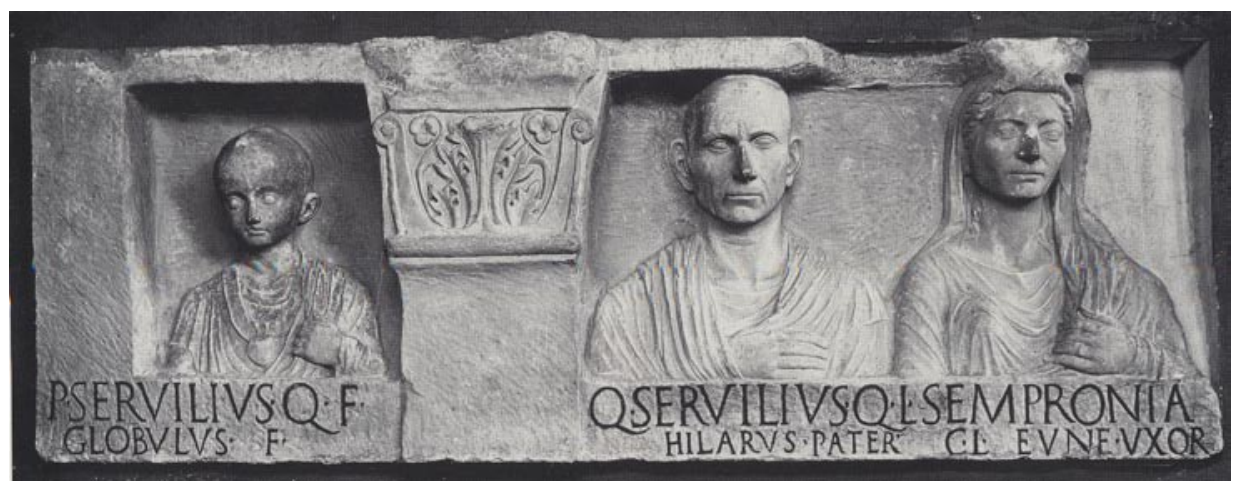

Figura 7: Relevo sepulcral dos Servilii, Roma, Museo Gregoriano Profano, inv.10491. (llustração em: KOCKEL, Valentin. Porträtreliefs stadtrömischer Grabbauten, II.51b).

Mas essa forma de auto-representação de escravos é excepcional. A regra são imagens de escravos da perspectiva senhorial - como acessórios, acompanhando o proprietário na vida e na morte. Por isso, escravos ou

ter centum ter denisque diebus |invisae parcae sollemnem celebrare diem|iamque ut esset gratus amicis|invidia superum cess(a)vit amari.

24 WREDE, Henning. Consecratio in formam deorum. Vergöttlichte Privatpersonen in der römischen Kaiserzeit. Mainz, 1981.

25 Roma, Museo Gregoriano Profano inv. 10491; v. KOCKEL, Valentin. Porträtreliefs stadtrömischer Grabbauten, p.141f. II. 51b. 
criados aparecem, muitas vezes, em monumentos sepulcrais, mosaicos, pinturas murais ou vasos. Faz parte de um monumento sepulcral a estátua de uma criada, sentada, com cabelo curto, que, com a mão esquerda, sustenta a cabeça, mostrando assim seu luto (Figura 8).$^{26}$ Essa figura faz parte dum conjunto sepulcral maior. Por causa da composição, podemos presumir que originalmente existia mais uma figura de menina assentada, que, junto com a primeira, ladeavam simetricamente o próprio túmulo, em um terraço sepulcral. O cabelo curto podia indicar que a criada era de fato uma escrava. ${ }^{27}$ Nesse caso, a própria obra oferece uma indicação sobre o estatuto da pessoa.

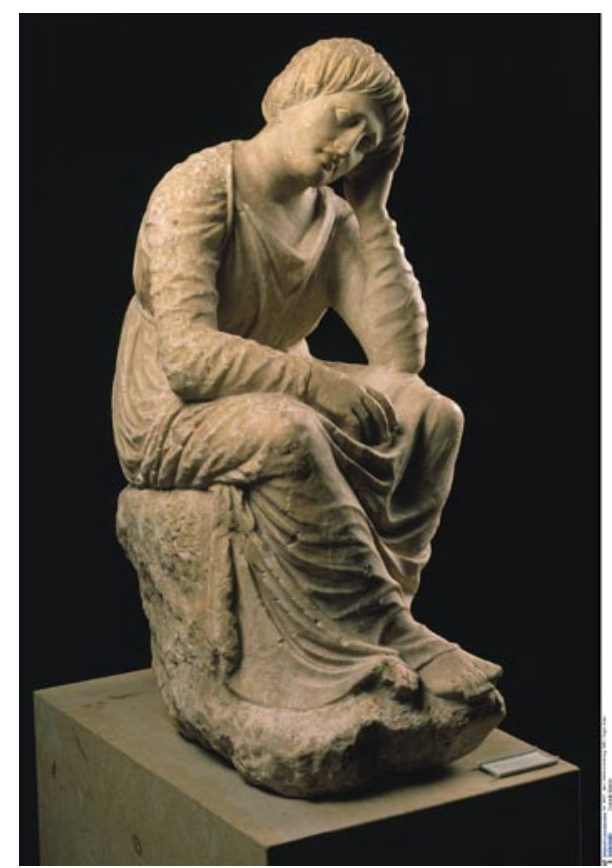

Figura 8: Statua duma criada estando de luto, Staatliche Museen zu Berlin, inv.SK 499.

(CBildarchiv Preussischer Kulturbesitz, Foto: Jürgen Liepe).

Em um relevo sepulcral de Neumagen (perto de Trier, Alemanha), podemos ver uma senhora cercada de suas criadas (Figura 9). ${ }^{28}$ Não se trata

26 Staatliche Museen zu Berlin, inv.SK 498; achado perto da freguesia Menidi (Demos Acharnai), perto de Atenas, datado do último terço do séc. IV a.C.; BLÜMEL, Carl. Katalog der griechischen Skulpturen des 5. und 4. Jahrhunderts v. Chr. Berlin, 1928 (Katalog der Sammlung antiker Skulpturen Bd.III), p.13ss. VEDDER, Ursula. Untersuchungen zur plastischen Ausstattung attischer Grabanlagen des 4. Jh. v. Chr. Frankfurt a.M. 1985, p.280 S 23.

27 KLEES, Hans. Sklavenleben im klassischen Griechenland. Stuttgart, 1998, p.70s.

28 BALTZER, Margot. Die Alltagsdarstellungen der treverischen Grabdenkmäler. Trierer Zeitschrift, v.46 p.64-71, 1983, para mais exemplos e paralelas. SCHUMACHER, Leonhard. Sklaverei in der Antike. Alltag und Schicksal der Unfreien, p.203-205. 
de cena diretamente ligada à morte da senhora, mas representa o dia-a-dia da sepultada. No centro está assentada uma mulher em cadeira de vime, cercada de quatro criadas. Não se pode reconhecer, com certeza, o estatuto das criadas (livres ou escravas). Nem o vestuario, nem a estatura, nem o corte do cabelo, nem a composição da cena permitem identificá-lo. Não se conservou qualquer inscrição que pudesse informá-lo. Mas, a partir de outros monumentos que trazem cenas parecidas e inscrições, sabemos que tais ornatrices muitas vezes eram escravas. ${ }^{29}$

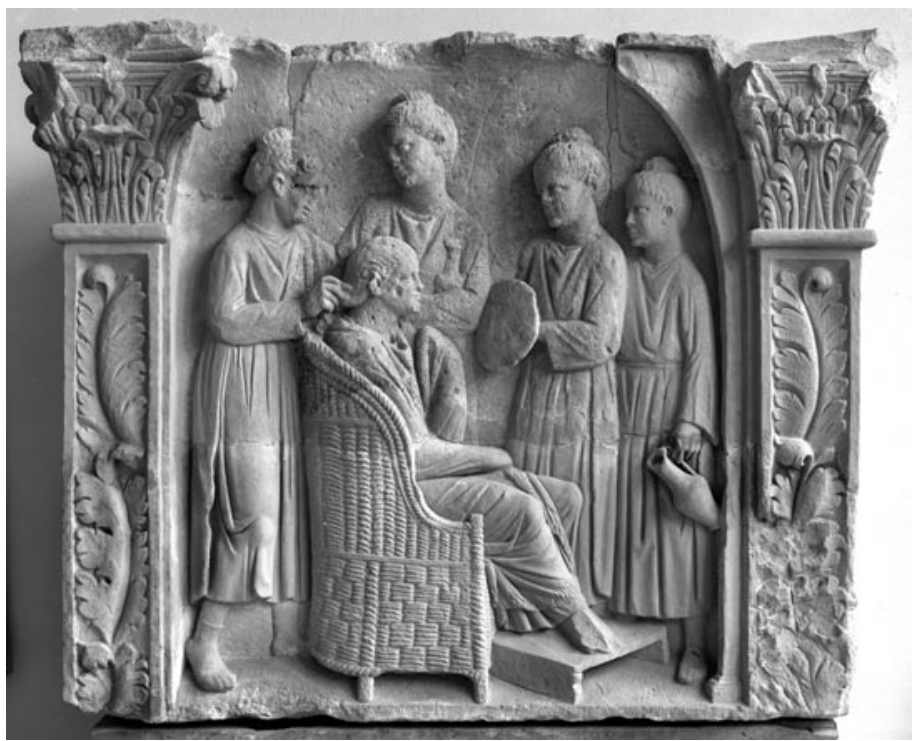

Figura 9: Neumagen. Cena de pentear do lado lateral da "coluna do casal". (@Rheinisches Landesmuseum Trier, Foto: H. Thörnig).

Poderíamos continuar essa série de imagens de criados, escravos e libertos ad infinitum, com imagens do dia-a-dia ou com imagens do banquete fúnebre. De vez em quando, o corte de cabelo ou uma estatura reduzida podem dar uma indicação do estatuto da pessoa representada, mas, na maioria dos casos, não se pode deduzir apenas a partir da própria imagem, sendo, para tanto, imprescindível a tradição escrita. O número

29 Por exemplo AE 1908, 40: Pollia C(ai)|(mulieris) I(iberta)/Urbana ornat(rix) de/Aemilianis ollas II/M(arcus) Calidius M(arci) I(ibertus) to(n)sor/Apol(I)oni(anus?) de Aemilianis aus Rom; AE 1911, $195=$ CIL XIV $5306=$ CIL I 3036: Agathemeris Manliae ser(va)/[Ac]hulea Fabiae ser(va) ornatrix/[Ca]letuche Vergiliae ser(va) ornatrix/Hilara Liciniae [ser(va) orn]atrix/Crheste Corn[eliae] ser(va) ornatrix/Hilara Seiae ser(va) ornatrix/Mosc(h)is ornatrix/Rufa Apeiliae ser(va) ornatrix/Chila ornatrix aus Ostia antica; CIL V 4194: Clodiae L(uci) I(ibertae)/Priscae ornat(rici)/Ascula publicu(s)/posuit; weitere Beispiele: CIL VI 3993, 3994; 4717, 5539; 5876; 7296; 7297; 8879; 8880; 8944; 8957; 8958; 8959; 8960; 8977; 9345; 9462a; 9729; 9732; 9734; 9735; 33099; 33370a; 33784; 37469; 37811; 37811a; CIL VIII 9428; CIL X 1935; 1941; 1942; AE 1955, 250. Vgl. auch die Schilderung bei Clemens von Alexandrien, paedagogus $3,26,3$. 
de criados ou escravos, o equipamento ou decoração deles, uma postura digna, símbolos de uma especialização e a fieldade ao senhor ou patrono, expressados em gestos de luto, são elementos que serviam à vontade de auto-representação senhorial e que ajudavam a mostrar o grau de sucesso econômico dele. De forma um pouco diferente, podemos constatar a mesma pretensão também no caso de imagens de cativos de guerra. Sobretudo mulheres e crianças eram raptadas pelos vencedores e vendidas como escravas. ${ }^{30}$ Essa prática era quase onipresente na Antiguidade, como se vê nas epopéias de Homero. ${ }^{31}$ Temos muitos exemplos da escravização de cativos de guerras na tradição tanto literária, quanto arqueológica. Por exemplo, dois relevos da coluna de Trajano, em Roma, mostram a captura de mulheres, homens e crianças por soldados romanos durante as guerras contra os Dácios (101-102, 105-106 d.C.). Imagens de cativos existem, também, em outros contextos arquitetônicos. ${ }^{32}$ Um exemplo particular é a pequena estatua de um negrinho (Figura 10) ${ }^{33}$ de cócoras. Os ferros em seus pés indicam que se tratava de um cativo. ${ }^{34}$ Também nestes casos, as obras plásticas servem à auto-representação de seus fundadores, embora não representem o sucesso econômico deles, mas sim um sentimento de superioridade vencedora. A pequena estátua do negrinho refletia mais um aspecto: já na Antiguidade houve tráfico de escravos africanos, ainda que a maioria dos escravos dos gregos e dos romanos não fosse constituída de negros, mas de procedentes da Ásia Menor, da Síria, da região do Mar Negro, da Gália, da Germânia e da Bretanha. ${ }^{35}$ São os "loiros e peludos na maneira dos eubeos"36 que, segundo Sinesio de Cirene, serviam como escravos dos romanos.

Em que resulta, então, o emprego de imagens de escravos, em adição à tradição escrita, na investigação sobre a escravidão antiga? Esta pergunta se põe, sobretudo, em vista do fato de que nós temos que nos apoiar, quase sempre, em fontes escritas, para definir com mais certeza o estatuto das pessoas representadas. Mas, os exemplos aqui apresentados mostram que os monumentos transportam, de uma maneira sutil, informações adicionais sobre a relação senhor-escravo e, também, sobre a auto-compreensão dos

30 V. WELWEI, Karl-Wilhelm. Sub corona vendere. Quellenkritische Studien zu Kriegsgefangenschaft und Sklaverei in Rom bis zum Ende des Hannibalkrieges unter Berücksichtigung des Nachlasses von Gottfried Prachner. Stuttgart 2000 (FAS 34); VOLKMANN, Hans. Die Massenversklavungen der Einwohner eroberter Städte in der hellenistischrömischen Zeit. Stuttgart, 1990 (FAS 22); SCHEIDEL, Walter. Frauen als Ware: Sklavinnen in der Wirtschaft der griechisch-römischen Welt. In: SPECHT, E. (ed.) Frauenreichtum. Die Frau als Wirtschaftsfaktor im Altertum. Reihe Frauenforschung, Wien, v.27, p.146-148, 1994.

31 WICKERT-MICKNAT, Gisela. Unfreiheit im Zeitalter der homerischen Epen. Wiesbaden, 1983 (FAS 16), p.55-58.

32 Ver os exemplos que apresenta SCHUMACHER, Leonhard. Sklaverei in der Antike. Alltag und Schicksal der Unfreien, p.65-71.

33 Boston, Museum of Fine Arts, inv. 018210; 1. Jh. v. Chr. - 1. Jh. n. Chr

34 SNOWDEN JR., Frank M. Blacks in Antiquity. Ethiopians in the Greco-Roman Experience. Cambridge Mass., 1970 II. 42.

35 BINSFELD, Andrea. Menschenhandel - Frauenhandel. In: HEINEN, H. (ed.) Menschenraub, Menschenhandel und Sklaverei in antiker und moderner Perspektive. Stuttgart, 2008, p.87f. com mais referências.

36 VON KYRENE, Synesios. Peri basileias, v.22 
senhores ou (às vezes, até) dos escravos. Sobretudo os raros monumentos que oferecem um ponto de vista do lado dos escravos, trazem uma perspectiva que, muitas vezes, inexiste nas fontes literarias da Antiguidade. Para se produzir uma noção detalhada da escravidão antiga é recomendável, então, se considerar todos os tipos de fontes possíveis, bem como tentar se empreender um cruzamento entre elas.

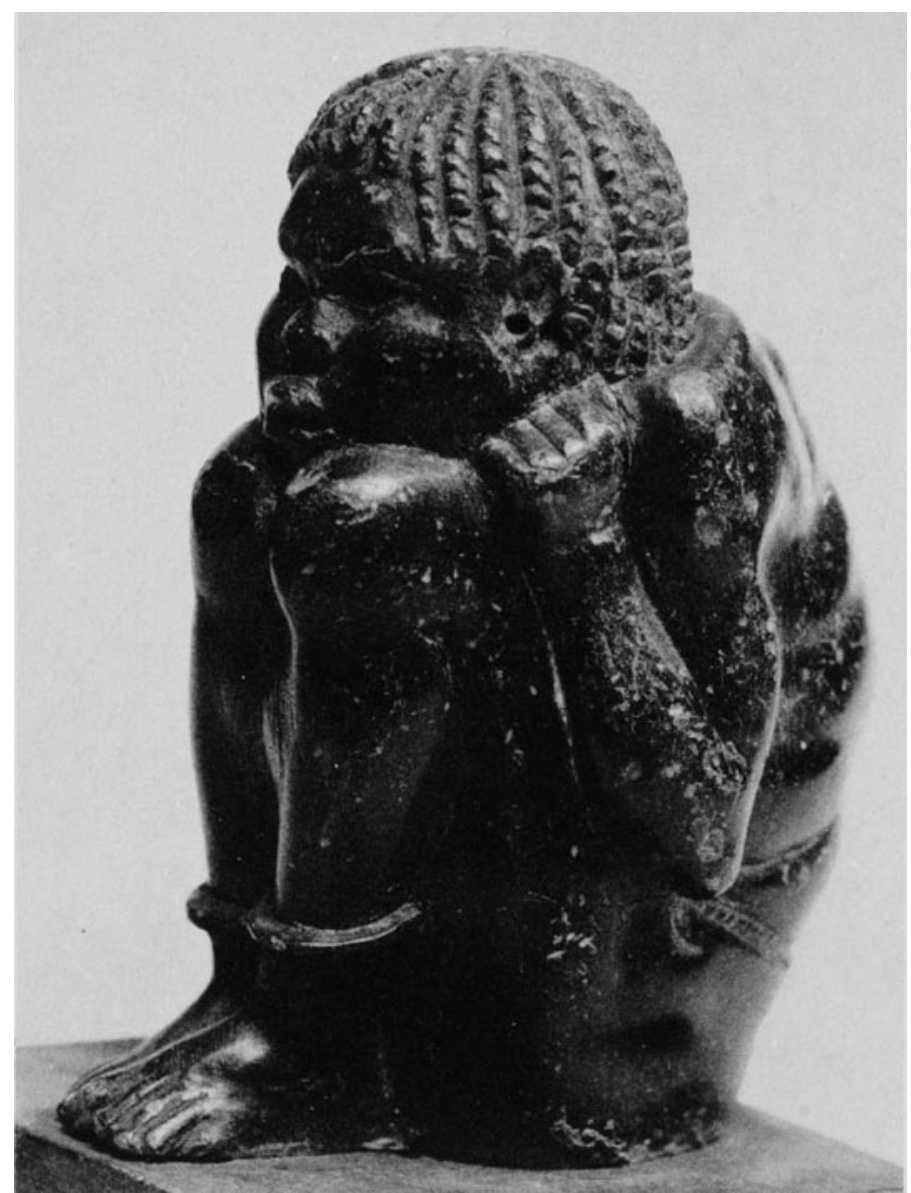

Figura 10: Figura de um escravo negrinho de cócoras. (@Boston Museum of Fine Arts; II. de: Sculpture in Stone. The Greek, Roman and Etruscan Collections of the Museum of Fine Arts Boston, Boston 1976, nr.112, p.71). 